\title{
Appraising the Impact of Hand and Knee Osteoarthritis on the Domains of Quality of Life among the Diabetic Patients - An Observational Research
}

\author{
Barsha Pathak Gadapani ${ }^{1}$, Rukman M. Manapurath ${ }^{2}$ \\ 1,2 Department of Community Medicine, KEM Hospital, Mumbai, Maharashtra, India.
}

\section{ABSTRACT}

\section{BACKGROUND}

Quality of life (QOL) measures have become a vital and frequently essential fragments to appraise health-care outcomes and is a powerful tool to determine the impact of healthcare as well as personal care for the population who are surviving with chronic diseases especially when ultimate cure for that specific disease is not conceived.

\section{METHODS}

This is a cross-sectional study where consecutive random sampling was utilised to select 258 diabetics from the general outpatient department (OPD) of a tertiary care center and QOL was evaluated among the diabetics and diabetics with osteoarthritis (OA) using modified Flanagan's QOL scale.

\section{RESULTS}

The mean QOL among diabetics was $88.28( \pm 2.62)$, mean QOL among diabetics with OA (hand) was $87.26( \pm 2.22)$, mean QOL among diabetics with OA (knee) was 85.37 $( \pm 2.14)$, mean QOL among diabetics with OA (knee and hand) was $83( \pm 2.33)$, mean QOL among diabetics with OA with radiological changes was $80.77( \pm 2.9)$.

\section{CONCLUSIONS}

The presence of more than one chronic disease significantly deteriorates the QOL. The domains of QOL are further affected when the chronic disease progresses further.

\section{KEY WORDS}

Quality of Life (QOL), Diabetes, Osteoarthritis, Chronic Diseases
Corresponding Author: Dr. Rukman M. Manapurath, Community Medicine, KEM Hospital, Mumbai, Maharashtra, India. E-mail: pathakbarsha@gmail.com

DOI: $10.14260 /$ jemds/2021/192

How to Cite This Article:

Gadapani BP, Manapurath RM. Appraising the impact of hand and knee osteoarthritis on the domains of quality of life among the diabetic patients - an observational research. J Evolution Med Dent Sci 2021;10(12):894-898, DOI: 10.14260/jemds/2021/192

Submission 13-09-2020,

Peer Review 24-01-2021,

Acceptance 02-02-2021,

Published 22-03-2021.

Copyright (C) 2021 Barsha Pathak Gadapani et al. This is an open access article distributed under Creative Commons Attribution License [Attribution 4.0 International (CC BY 4.0)] 


\section{BACKGROUND}

Diabetes mellitus is one of the most common chronic metabolic disorders and has a dramatic increase in the prevalence rate across the globe. ${ }^{1}$ The global prevalence of diabetes mellitus in the year 2013 was around 382 million, which is expected to rise up to 592 million by the year 2035 . India has 65.10 million adults suffering from diabetes mellitus and the predicted affliction of cases to 79.4 million by $2030.2,3$ Diabetic patients suffer from musculoskeletal pain and osteoarthritis which has a life-time prevalence of 30 - $50 \%$ among them and one of the most common adverse manifestation. ${ }^{4,5}$ Diabetes itself has a very strong impact on degrading the quality of life among the chronic patient. Yet again, $\mathrm{OA}$ is associated with substantial disease burden due to pain, functional decline and increase in the morbidity. In the major studies conducted all over the world, OA is found as a common disability and painful comorbid condition which has a stronger impact on quality of life and its prevalence is quite higher in developing countries like India.5,6 This day and age, quality of life measures have become a vital and frequently essential fragment to appraise health-care outcomes and is a powerful tool to determine the impact of health-care as well as personal care for the population who is surviving with chronic diseases especially when ultimate cure for that specific disease is not conceived. 6 People with chronic diseases suffers from physical, mental, financial and social instabilities, hence, it is important to attain a holistic approach while managing such patients. ${ }^{7}$ There are a lot of literatures which evaluate the impact of chronic disease on psychosocial domain of the affected people however, inclusion of broader perspective including non-health elements which has powerful influences on satisfaction among chronically ill-people, is need of the hour. ${ }^{8}$ Revicki and colleagues define QOL as "a broad range of human experiences related to one's overall well-being. It implies value based on subjective functioning in comparison with personal expectations and is defined by subjective experiences, states and perceptions. ${ }^{7}$ The Quality of life Scale (QOLS) first developed by American psychologist John Flanagan is a 15-item instrument measuring five conceptual domains of quality of life: material and physical well-being, relationships with other people, social, community and civic activities, personal development and fulfilment, and recreation.7 Later on this QOL tool was further expanded by addition of the 16-item: Independence, the ability to do for yourself and tool has 7 designated responses for each domain.

The QOLS can be applied to study healthy adults and chronic patients suffering from chronic obstructive pulmonary diseases (COPD), rheumatic diseases, osteoarthritis, juvenile rheumatoid arthritis, fibromyalgia, psoriasis, spinal cord injury, urinary stress incontinence, posttraumatic stress disorder, and diabetes. ${ }^{7-9}$ This instrument needs 5 - 10 minutes for interviewing the study sample and it is scored by adding up the score to yield a total score which ranges from 16 to $112.6^{6-8}$
In our study we have included this 16-item QOL tool to measure the various domains among patients who are suffering from diabetes and diabetics additionally suffering from osteo-arthritis $(\mathrm{OA})$ residing in a metropolitan city. We have tried to analyse the impact of chronic diseases on the selected sample and the maximally affected domain of life by comparing the QOL among diabetic patient and diabetic patient additionally suffering from OA. QOL evaluations have become a significant element extending beyond the traditional variables in health care system. ${ }^{8}$ Within medicine, improving overall quality of life and health status is an imperative and crucial objective of treatment, and an appropriate outcome for health care interventions.

\section{METHODS}

A cross-sectional study design was employed to assess the QOL among the diabetic mellitus (type I and II) and the diabetes mellitus-DM (type 1 \& type II) suffering from OA. The study was conducted from August 2019 to November 2019 in general OPD during OPD timings, of a tertiary care centre, Mumbai, Maharashtra, India. The study was approved by the ethical review board of Seth G.S. Medical College and K.E.M. Hospital, Mumbai, Maharashtra. All participants gave written consent prior to participating in the baseline interview.

\section{Participants}

This study involved 258 diabetic patients above the age of 21 years. Sample was calculated by using formula $\left(\mathrm{N}=4 \mathrm{PQN} / \mathrm{e}^{2}\right.$ $(\mathrm{N}-1)+4 \mathrm{PQ})$, where prevalence of OA in DM was $29.5 \%$ and allowable error as $10 \%$. Consecutive sampling technique was used which is a type of non-probability sampling and allows every subject meeting the criteria of inclusion being selected until the required sample size was achieved. This technique was used to collect sample from general OPD of a tertiary care centre. The data was collected via a pre-validated modified version of Flanagan's scale for QOL after obtaining necessary written consent from the participants. All study participants were diabetics and OA were screened by using American College of Rheumatology (ACR) scale and radiological investigation (knee only).

After the necessary screening tests the participants were categorised into: Diabetics with OA (hand), diabetics with OA (knee), diabetics with OA (hand and knee) and diabetics with OA (significant radiological findings). The interview lasted for 10 - 12 mins (per patient) and was conducted in a comfortable room of general OPD (8.30 am to $12.30 \mathrm{pm}$; Days: Monday to Saturday). The patients whose radiological report were pending was requested to visit general OPD with the X-ray report during the OPD timings any day between Monday to Saturday and transportation charges for the follow-up visit was provided to these study participants.

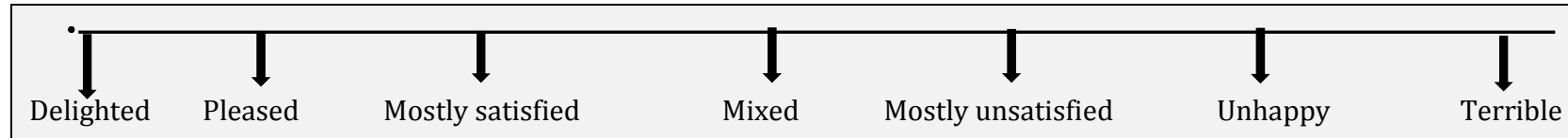




\begin{tabular}{|c|c|c|c|c|c|c|c|}
\hline हूँ & 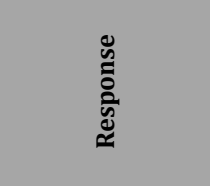 & 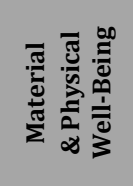 & 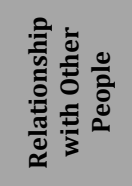 & क & 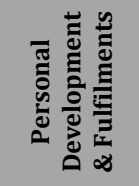 & 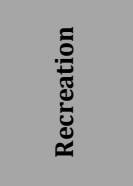 & 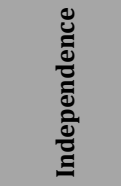 \\
\hline \multirow{9}{*}{ OA (hand) } & & $(N=65)$ & $(N=65)$ & $(\mathrm{N}=65)$ & $(N=65)$ & $(N=65)$ & $(\mathrm{N}=65)$ \\
\hline & Delighted & $3(4.6 \%)$ & $6(9.2 \%)$ & 0 & 0 & 0 & $2(3.1 \%)$ \\
\hline & Pleased & $8(12.3 \%)$ & $22(33.8 \%)$ & $3(4.6 \%)$ & $3(4.6 \%)$ & $2(3.1 \%)$ & $5(7.7 \%)$ \\
\hline & Mostly satisfied & $53(81.5 \%)$ & 37 (56.9\%) & 14 (21.5\%) & 47 (72.3\%) & 17 (26.2 \%) & $56(86.2 \%)$ \\
\hline & Mixed & $1(1.5 \%)$ & 0 & 48 (73.8 \%) & 15 (23.1\%) & $43(66.2 \%)$ & $2(3.1 \%)$ \\
\hline & Mostly not satisfied & 0 & 0 & 0 & 0 & $3(4.6 \%)$ & $0(0 \%)$ \\
\hline & Un-happy & 0 & 0 & 0 & 0 & 0 & 0 \\
\hline & Terrible & 0 & 0 & 0 & 0 & 0 & 0 \\
\hline & & $(N=37)$ & $(\mathrm{N}=37)$ & $(N=37)$ & $(\mathrm{N}=37)$ & $(N=37)$ & $(N=37)$ \\
\hline \multirow{7}{*}{ OA (knee) } & Delighted & 0 & 0 & 0 & 0 & 0 & 0 \\
\hline & Pleased & $2(5.4 \%)$ & 0 & 0 & 0 & 0 & 0 \\
\hline & Mostly satisfied & $5(13.5 \%)$ & 30 (81.1\%) & 11 (29.7\%) & 7 (18.9\%) & 0 & $8(21.6 \%)$ \\
\hline & Mixed & $17(45.9 \%)$ & $6(16.2 \%)$ & $3(8.1 \%)$ & 25 (67.6 \%) & 18 (48.6\%) & $29(78.4 \%)$ \\
\hline & Mostly not satisfied & 12 (32.4 \%) & $1(2.7 \%)$ & 13 (35.1\%) & 5 (13.5\%) & 11 (29.7\%) & 0 \\
\hline & Un-happy & 0 & 0 & $6(16.2 \%)$ & 0 & $8(21.6 \%)$ & 0 \\
\hline & Terrible & $1(2.7 \%)$ & 0 & $4(10.8 \%)$ & 0 & 0 & 0 \\
\hline \multirow{9}{*}{$\begin{array}{c}\text { OA } \\
\text { (hand and } \\
\text { knee) }\end{array}$} & & $(\mathrm{N}=23)$ & $(N=23)$ & $(N=23)$ & $(\mathrm{N}=23)$ & $(\mathrm{N}=23)$ & $(\mathrm{N}=23)$ \\
\hline & Delighted & 0 & 0 & 0 & 0 & 0 & 0 \\
\hline & Pleased & 0 & 0 & 0 & 0 & 0 & 0 \\
\hline & Mostly satisfied & $3(13 \%)$ & $11(47.8 \%)$ & 0 & $1(4.3 \%)$ & 0 & 0 \\
\hline & Mixed & $8(34.8 \%)$ & $6(26.1 \%)$ & 14 (60.9\%) & 12 (52.2\%) & $5(21.7 \%)$ & $12(52.2 \%)$ \\
\hline & Mostly not satisfied & $2(8.7 \%)$ & 4 (17.4 \%) & $1(4.3 \%)$ & 7 (30.4 \%) & $6(26.1 \%)$ & $6(26.1 \%)$ \\
\hline & Un-happy & 9 (39.1 \%) & $2(8.7 \%)$ & $6(26.1 \%)$ & $3(13 \%)$ & $6(26.1 \%)$ & $3(13 \%)$ \\
\hline & Terrible & $1(4.3 \%)$ & 0 & $2(8.79 \%)$ & 0 & $6(26.1 \%)$ & $2(8.7 \%)$ \\
\hline & & $(\mathrm{N}=22)$ & $(\mathrm{N}=22)$ & $(\mathrm{N}=22)$ & $(\mathrm{N}=22)$ & $(\mathrm{N}=22)$ & $(\mathrm{N}=22)$ \\
\hline \multirow{7}{*}{$\begin{array}{c}\mathrm{OA} \\
\text { (radiologically } \\
\text { positive findings) }\end{array}$} & Delighted & 0 & 0 & 0 & 0 & 0 & 0 \\
\hline & Pleased & 0 & 0 & 0 & 0 & 0 & 0 \\
\hline & Mostly satisfied & $1(4.5 \%)$ & 4 (18.2 \%) & 0 & $3(13.6 \%)$ & 0 & 0 \\
\hline & Mixed & $1(4.5 \%)$ & $11(50 \%)$ & $3(13.6 \%)$ & $4(18.2 \%)$ & 0 & $11(50 \%)$ \\
\hline & Mostly not satisfied & 9 (40.9\%) & $5(22.7 \%)$ & $1(4.5 \%)$ & 12 (54.5\%) & $3(13.6 \%)$ & $6(27.3 \%)$ \\
\hline & Un-happy & $9(40.9 \%)$ & $2(9.1 \%)$ & $12(54.5 \%)$ & $3(13.6 \%)$ & $13(59.1 \%)$ & $3(13.6 \%)$ \\
\hline & Terrible & $2(9.1 \%)$ & 0 & $6(27.3 \%)$ & 0 & $6(27.3 \%)$ & $2(9.1 \%)$ \\
\hline
\end{tabular}

\begin{tabular}{|c|c|c|c|c|c|c|c|}
\hline $\begin{array}{l}\text { Scale } \\
\text { Ratings }\end{array}$ & Status & $\begin{array}{c}\text { Material \& Physical } \\
\text { Well-Being ( }=133 \text { ) }\end{array}$ & $\begin{array}{c}\text { Relationship with } \\
\text { Other People ( }=133 \text { ) }\end{array}$ & $\begin{array}{l}\text { Social, Community, Civic } \\
\text { Activities }(\mathrm{N}=133)\end{array}$ & $\begin{array}{l}\text { Personal Development \& } \\
\text { Fulfilments }(\mathrm{N}=133)\end{array}$ & $\begin{array}{c}\text { Recreation } \\
(\mathrm{N}=133)\end{array}$ & $\begin{array}{l}\text { Independence } \\
(\mathrm{N}=133)\end{array}$ \\
\hline Delighted & Diabetes & 4 & 8 & 3 & 4 & 5 & 3 \\
\hline Pleased & Diabetes & $\begin{array}{c}3 \% \\
13 \\
9.8 \%\end{array}$ & $\begin{array}{c}0.0 \% \\
27 \\
20.3 \%\end{array}$ & $\begin{array}{l}1.2 \% \\
7 \\
5.3 \%\end{array}$ & $\begin{array}{l}1.6 \% \\
8 \\
6.0 \%\end{array}$ & $\begin{array}{c}1.9 \% \\
12 \\
9 \%\end{array}$ & $\begin{array}{c}2.3 \% \\
16 \\
12 \%\end{array}$ \\
\hline $\begin{array}{c}\text { Mostly } \\
\text { satisfied }\end{array}$ & Diabetes & $\begin{array}{c}72 \\
54.1 \%\end{array}$ & $\begin{array}{c}86 \\
64.7 \%\end{array}$ & $\begin{array}{c}60 \\
45.1 \%\end{array}$ & $\begin{array}{c}80 \\
60.2 \%\end{array}$ & $\begin{array}{c}57 \\
42.9 \%\end{array}$ & $\begin{array}{c}86 \\
64.7 \%\end{array}$ \\
\hline Mixed & Diabetes & $\begin{array}{c}27 \\
20.3 \%\end{array}$ & $\begin{array}{c}8 \\
6.0 \%\end{array}$ & $\begin{array}{c}45 \\
33.8 \%\end{array}$ & $\begin{array}{c}7 \\
5.3 \%\end{array}$ & $\begin{array}{c}48 \\
36.1 \%\end{array}$ & $\begin{array}{c}24 \\
18 \%\end{array}$ \\
\hline $\begin{array}{c}\text { Mostly } \\
\text { not } \\
\text { satisfied }\end{array}$ & Diabetes & $\begin{array}{c}10 \\
7.5 \%\end{array}$ & $\begin{array}{c}3 \\
2.3 \%\end{array}$ & $\begin{array}{c}9 \\
6.8 \%\end{array}$ & $\begin{array}{c}33 \\
24.8 \%\end{array}$ & $\begin{array}{c}6 \\
4.5 \%\end{array}$ & $\begin{array}{c}3 \\
2.3 \%\end{array}$ \\
\hline Unhappy & Diabetes & $\begin{array}{c}6 \\
4.5 \%\end{array}$ & $\begin{array}{c}1 \\
0.8 \%\end{array}$ & $\begin{array}{c}7 \\
5.3 \%\end{array}$ & $\begin{array}{c}1 \\
0.8 \%\end{array}$ & $\begin{array}{c}4 \\
3 \%\end{array}$ & $\begin{array}{c}1 \\
0.8 \%\end{array}$ \\
\hline Terrible & Diabetes & $\begin{array}{c}1 \\
0.8 \%\end{array}$ & $\begin{array}{c}0 \\
0 \%\end{array}$ & $\begin{array}{r}2 \\
1.5 \%\end{array}$ & $\begin{array}{c}0 \\
0 \%\end{array}$ & $\begin{array}{c}0 \\
0 \%\end{array}$ & $\begin{array}{l}0 \\
0 \%\end{array}$ \\
\hline
\end{tabular}

\begin{tabular}{|c|c|c|c|c|}
\hline SI. No & Domains & Status & $\begin{array}{l}\text { Chi- } \\
\text { Square }\end{array}$ & P-Value \\
\hline 1. & $\begin{array}{l}\text { Material \& physical well- } \\
\text { being }\end{array}$ & $\begin{array}{c}\text { Diabetes only } \\
\text { diabetes and } \mathrm{OA}\end{array}$ & 14.16 & $<0.001$ \\
\hline 2. & $\begin{array}{l}\text { Relationship with other } \\
\text { people }\end{array}$ & $\begin{array}{c}\text { Diabetes only } \\
\text { diabetes and OA }\end{array}$ & 85.11 & $<0.001$ \\
\hline 3. & $\begin{array}{l}\text { Social, community, civic } \\
\text { activities }\end{array}$ & $\begin{array}{c}\text { Diabetes only } \\
\text { diabetes and OA }\end{array}$ & 120 & $<0.001$ \\
\hline 4. & $\begin{array}{l}\text { Personal development \& } \\
\text { fulfilments }\end{array}$ & $\begin{array}{c}\text { Diabetes only } \\
\text { diabetes and OA }\end{array}$ & 98.28 & $<0.001$ \\
\hline 5. & Recreation & $\begin{array}{c}\text { Diabetes only } \\
\text { diabetes and OA }\end{array}$ & 158.2 & $<0.001$ \\
\hline 6. & Independence & $\begin{array}{c}\text { Diabetes only } \\
\text { diabetes and OA }\end{array}$ & 182.16 & $<0.001$ \\
\hline
\end{tabular}

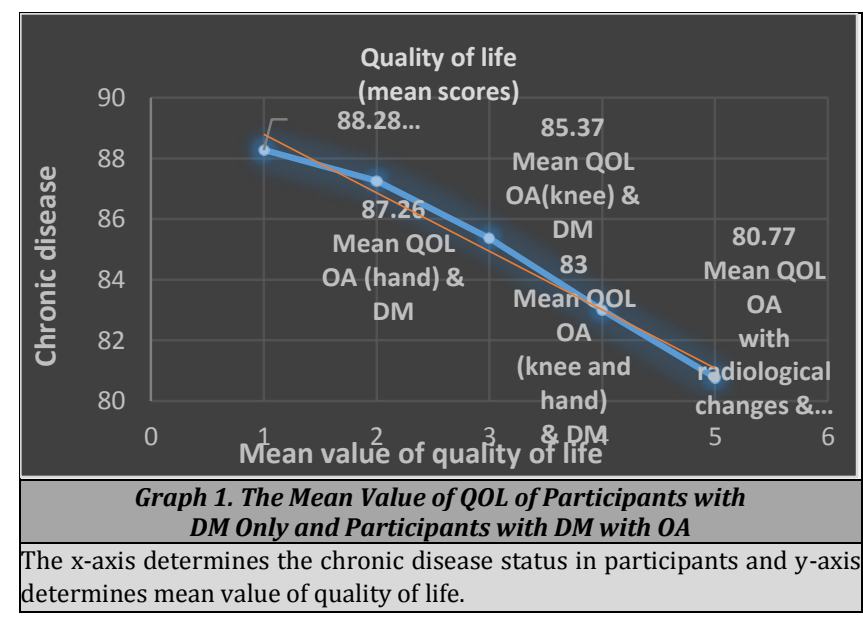




\section{Statistical Analysis}

All the statistical analysis was performed using SPSS version 16 . Frequency and percentages were utilised to present the categorical variables and appropriate graphical representation were made wherever required. The internal reliability of the scale was assessed by Cronbach's alpha co-efficient. The QOLS was scored by adding up the score on each item to generate a total score for the instrument. Score ranged from 16 to 112 and no specific scoring software was utilised for calculating the total score for QOL. Chi-square test was utilised to find the association between the domains of quality of life and presence of DM with OA and DM alone and P-value of $<0.05$ was considered statistically significant for the entire study.

\section{RESULTS}

Table 1 specifies that after application of Australian/Canadian Osteoarthritis Hand Index (AUSCAN) scale and radiologically investigation, we found 65 diabetic patients suffering from hand OA, 33 diabetic patient suffering from knee OA, 23 diabetic patients suffering from hand \& knee $\mathrm{OA}$ and 22 diabetics among them had radiologically signs of OA. The QOL domains were analysed, and various response percentages were marked as shown in the table (Table 1). Out of 258 study participants 133 participants had only diabetes and 125 participants had both diabetes and OA. The QOL domains were analysed, and various response percentages were marked as shown in the table. (Table 2). Table 3 shows that the presence of two chronic diseases in the same individual has significantly downgraded all the domains of QOL.

Graph 1 signifies the mean of total score of QOL among the diabetics and diabetics with OA. The mean QOL among diabetics was 88.28 ( \pm 2.62$)$, mean QOL among diabetics with OA (hand) was $87.26( \pm 2.22)$, mean QOL among diabetics with OA (knee) was $85.37( \pm 2.14)$, mean QOL among diabetics with OA (knee and hand) was $83( \pm 2.33)$, mean QOL among diabetics with OA and radiological changes was $80.77( \pm 2.9)$. Hence, it determines the steady downfall of the QOL with the progression of the chronic disease.

\section{DISCUSSION}

In this study, quality of life was assessed by the modified Flanagan's QOL scale which has 6 domains and 7 responses (on Likert's scale). After analysing the data, we found that the 133 study participants suffered from one chronic condition i.e. diabetes and 125 study participants suffered from diabetes with osteoarthritis (OA) both. Furthermore, with the help of ACR scale and radiological investigations we categorised the $\mathrm{OA}$ into hand $\mathrm{OA}(\mathrm{N}=65)$, knee $\mathrm{OA}(\mathrm{N}=37)$, combination of hand and knee OA $(\mathrm{N}=23)$ and $\mathrm{OA}$ with radiological changes $(\mathrm{N}=22)$. The modified Flanagan's QOL scale was applied to all the participants of the study $(\mathrm{N}=258)$ and we got significant variation in terms of: QOL means (with SD) and responses of the various QOL domains.

Study participants who suffered from both diabetics and OA had QOL mean score of 85 (approx.) compared to mean QOL score among diabetics i.e. 88.28. The OA was categorised into four criteria and the diabetics with $\mathrm{OA}$ (hand) were mostly satisfied with the following domains of QOL: Material \& hand was $83( \pm 2.33)$ and the least mean of QOL was $80.77( \pm 2.9)$ found among diabetics with $\mathrm{OA}$ and radiological physical wellbeing (81.5\%), relationship with other people (56.9\%), personal development and fulfilments $(72.6 \%)$ and independence (86.2\%) [Table 1]. Nevertheless, among the study participants with OA (hand) mixed response were shared for social, community and civic activities domain (73.8\%) and recreation domain (66.2\%) [Table 1]. Most of the study participants with OA (knee) had a mixed response for various domains of QOL except relationship with other people where the participant's response was mainly satisfactory (Table 1). More than $50 \%$ of the diabetic participants with OA (knee and hand) had mixed response to domains of relationship with other people and personal development and fulfilments but negative responses for various other domains were higher e.g. $26 \%$ of participants were un-happy with social, community and civic activities and $26.1 \%$ participants responded to have terrible experience with recreation domain of QOL [Table 1]. The diabetic participants with radiologically significant OA had greater negative responses. More than $50 \%$ of the participants were un-happy with social, community and civic activities and recreation domain of QOL. More than $50 \%$ had a mixed response to other significant domains of QOL [Table

1]. Most of the diabetic sufferers had satisfactory response to the six domains of Flanagan's QOL scale. Relationship with other people and personal developments \& fulfilments are the two domains where maximum responses of delighted and pleased were obtained from the diabetic sufferers. Yet again, recreation ( $42.9 \%$ responded as mostly satisfied) and social, community, civic activities (45.1\% responded as mostly satisfied) domain appear to be affected adversely among the diabetics. [Table 2]. Thereafter Graph 1 shows the mean and standard deviation (SD) of QOL among the study participants. The mean QOL among diabetics was $88.28( \pm 2.62)$, followed by diabetics with hand OA i.e., $87.26( \pm 2.22), 85.37( \pm 2.14)$ mean QOL among diabetics with OA (knee), then mean of diabetics with OA (knee) and changes, indicating a steady down-gradation of QOL. The findings of the study revealed significant association between QOL and its 6 domains of the scale suggesting there is lower scores or increased difficulty in study subjects with OA and DM together compared to those with DM alone (Table 1, Table 2 and Table 3). Similar kind of findings has been found in the recent and past studies performed among the chronic disease sufferers. 9,8,10,11

From the result above, the most significant domains to be impacted with presence of chronic diseases were social, community, civic activities and recreation. Past studies has demonstrated the total scores of QOL among normal healthy people lies above $90 .{ }^{7}$ This study proves that the domains of QOL gets adversely affected among the sufferers of more than one chronic disease and gradually progressing chronic diseases. This can further impact the mental health of the affected people, as social life is mostly disrupted, leading to further deterioration of the QOL. Many previous studies have highlighted that OA is very common among the diabetic sufferers. Hence, if necessary, preventive strategies and proper screening test are performed among the diabetic population, the complications can be withheld and QOL can be retained. Proper information and guidance to the chronic diseased by using various information, education and communication (IEC) materials, Web / Internet based 
training program, interesting workshops etc. at an early disease stage should be mandated in the healthcare cantres. ${ }^{11}$

\section{CONCLUSIONS}

The QOL scores among the chronic diseased population was lower than the general population. With the presence of more than one chronic disease the quality of life degrades significantly. In this study, presence of OA among diabetic subjects adversely impacted the various domains of QOL social, community, civic activities and recreation. The diabetics who had radiologically significant $\mathrm{OA}$ were worst affected and had negative scores in various domains of QOL. Early preventive strategies and motivation among diabetics for maintaining regular follow-ups, timely medications, and improving lifestyle will have positive outcome in their health status. Hence, diabetic people should be given proper counselling about the immediate and long-term complications and importance of maintaining a good quality of life.

\section{Limitations}

Limitations of the study are to be viewed with respect to the sample size, which was small and the results cannot be generalised to the all chronic patients living in a metropolitan areas.

Data sharing statement provided by the authors is available with the full text of this article at jemds.com.

Financial or other competing interests: Grant received from Diamond Jubilee Society Trust, Seth GSMC \& KEMH, Mumbai, Maharashtra.

Disclosure forms provided by the authors are available with the full text of this article at jemds.com.

We sincerely thank the Dept. of Community Medicine, KEM Hospital for providing adequate $\&$ convenient place for conducting the interviews in GOPD.

\section{REFERENCES}

[1] Gadsby R. Epidemiology of diabetes. Adv Drug Deliv Rev 2002;54(9):1165-72.

[2] Forouhi NG, Wareham NJ. Epidemiology of diabetes. Medicine (Abingdon) 2014;42(12):698-702.

[3] Kaveeshwar SA, Cornwall J. The current state of diabetes mellitus in India. Australas Med J 2014;7(1):45-8.

[4] Eivazi M, Abadi L. Low back pain in diabetes mellitus and importance of preventive approach. Heal Promot Perspect 2012;2(1):80-8.

[5] Miksch A, Hermann K, Rölz A, et al. Additional impact of concomitant hypertension and osteoarthritis on quality of life among patients with type 2 diabetes in primary care in Germany-a cross-sectional survey. Health Qual Life Outcomes 2009;7(1):19.

[6] Bhaskar A, Manjula VD, Joseph J. Study on morbidities and functional disabilities of elderly in rural area of Kottayam. J Evol Med Dent Sci 2014;3(37):9601-9.

[7] Vavrik P, Landor I, Popelka S, et al. N??rodn?? registr kloubnich n??hrad CR n??hrady kycelniho kloubu. Acta Chir Orthop Traumatol Cech 2010;(Suppl 77):1-75.

[8] De Souza LB, Corrente JE. Evaluation of the flanagan quality of life scale for older adults. International Journal of Science, Commerce and Humanities 2013;1(4):10-20.

[9] Neumann L, Buskila D. Measuring the quality of life of women with fibromyalgia: a hebrew version of the quality of life scale. J Musculoskelet Pain 1997;5(1):5-16.

[10] Dijkers MPJM. Quality of life of individuals with spinal cord injury: a review of conceptualization, measurement and research findings. J Rehabil Res Dev 2005;42(3 Suppl 1):87-110.

[11] Uran BNO, Aykar S, Yildirim Y, et al. The effect of web-based education on disease activity, symptom management and quality of life in patients with inflamatory bowel disease: randomized-controlled study. Medical Science 2019;23(98):415-431. 